\title{
PROBABILISTIC EVALUATION OF CONCRETE STRAINS FOR ASSESSING PRESTRESSING LOSS IN NUCLEAR CONTAINMENT SEGMENTS
}

\author{
University of Waterloo \\ Waterloo, ON, Canada \\ e-mail: gbalomen@uwaterloo.ca \\ ${ }^{\dagger}$ University of Waterloo \\ Waterloo, ON, Canada \\ e-mail: mdpandey@uwaterloo.ca
}

GEORGIOS P. BALOMENOS ${ }^{*}$ AND MAHESH D. PANDEY ${ }^{\dagger}$

Key words: Prestressed Concrete, Nuclear Containment Wall Segments, Probabilistic Analysis, Monte Carlo Simulation, ABAQUS

\begin{abstract}
The main function of the nuclear containment structure is to prevent any radioactive leakage to the environment. The Canadian Standard Association (CSA) provides guidelines for the periodic inspection of the containment prestressed system. However, these inspections are not possible to assess directly the condition of the bonded tendons. Thus, the main objective of this research is to investigate if concrete strain measurements, obtained during inspections, can be used for evaluating the prestressing loss of these bonded systems. First, the fracture energy approach is applied for modelling the tensile strength of the concrete, using the concrete damage plasticity model. The finite element analysis (FEA) results are in good agreement compared to the test results, indicating the accuracy of the adopted modeling approach. Then, probabilistic analysis is applied, since the measured concrete strains are expected to have a distribution due to several uncertainties. The results indicate that the prestressing loss of bonded tendons seems to affect the concrete strain distribution. The proposed probabilistic framework can be used as an approach for estimating the magnitude of the prestressing loss, during periodic inspections.
\end{abstract}

\section{INTRODUCTION}

Nuclear reactors are housed by a prestressed concrete containment structure (Figure 1), which is usually circular and consists of a concrete base, a cylindrical perimeter wall, a ring beam and a dome [1]. The main function of the containment is to prevent any radioactive leakage to the environment, which may occur during the loss of coolant accident (LOCA) [2]. Therefore, the containment is made of pretsressed concrete, in order to ensure integrity and tightness in case of an accident [3]. However, prestressing losses due to material deformations, e.g., relaxation of tendons, creep and shrinkage of concrete, can affect the integrity of the containment [2].

The CSA inspection guidelines [4] provide approaches for the periodic inspection of the containment prestresed system. These are nondestructive techniques, where the containment is pressurized and the stress-strain is measured, in order to assess the strength and design criteria of the containment and the leak 
tightness of the containment boundary [5]. Although, these inspections are not possible to assess directly the condition of the bonded tendons, the measured concrete strains during these pressure tests may provide information for the prestressing loss of the bonded tendons. However, these measured strains during a pressure test will have a distribution due to uncertainties. Therefore, this study investigates the change of the concrete strain distribution with respect to the prestressing loss in tendons.

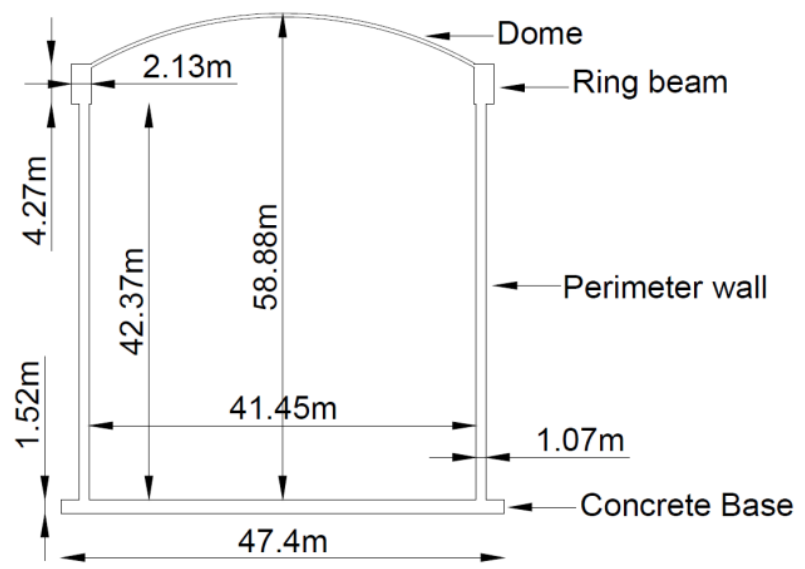

Figure 1: Prestressed concrete containment.

\section{WALL SEGMENTS}

A series of tests were conducted on prestressed concrete wall segments, as a part of a research program at the University of Alberta, in order to investigate the overpressure effect of the containment structures [6]. In this study, segment 2 is selected which represents the prestressing conditions and loading of the cylindrical wall of the containment structure (Figure 1). Segment 2 is a square panels of $800.1 \mathrm{~mm}$ with a width of $266.7 \mathrm{~mm}$. These dimensions correspond to a quarter scale of the prototype containment. Thus, each segment has a width of $266.7 \mathrm{~mm}$ and a tendon duct size almost one-fourth the size of ducts used in the prototype containment, while the lateral dimensions were chosen as three times the wall thickness (Figure 2).

The selected segment is prestressed in both directions, where the hoop direction consists of 4 tendons with 7 smooth wires in each tendon and the axial direction consists of 3 tendons with 6 smooth wires in each tendon. Each smooth wire has a diameter of $7.01 \mathrm{~mm}$, yield strength of $1627 \mathrm{Mpa}$, ultimate strength of $1820 \mathrm{Mpa}$ and modulus of elasticity of 200 GPa. Apart from the tendons, the segment is reinforced with two grids of non-prestressed bars in each direction (Figure 3).

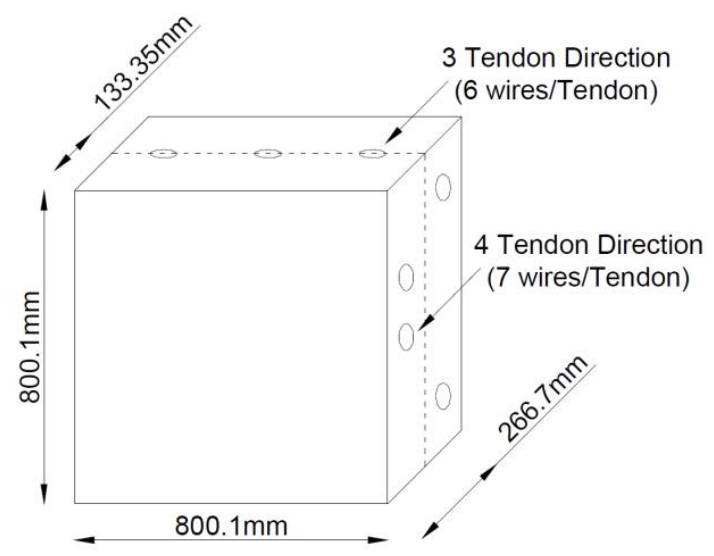

Figure 2: Wall segment with prestressed reinforcement.

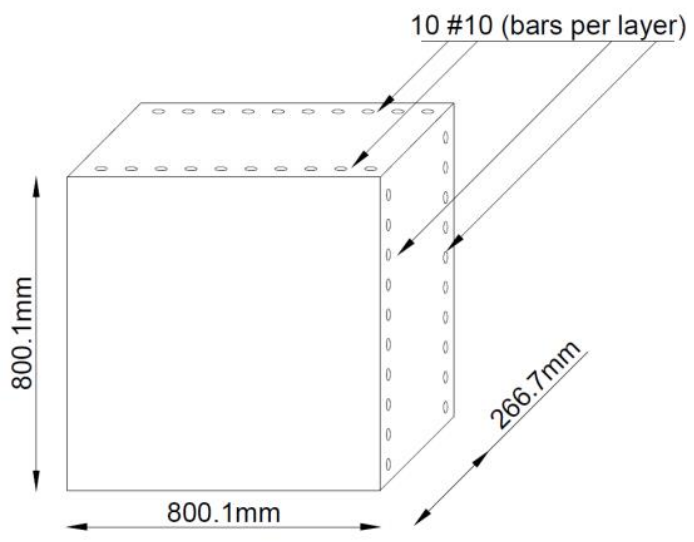

Figure 3: Wall segment with non-prestressed reinforcement.

The concrete strength and the modulus of elasticity for segment 2 are $31 \mathrm{MPa}$ and 27,027 MPa, respectively [6].

The prototype containment structure was designed for an internal pressure of $124 \mathrm{kPa}$ [1]. Considering that the containment has an inner-radius to wall-thickness ratio bigger than 10, thin-wall analysis can be used for calculating the developed stresses, and subsequently the developed forces, under a predefined pressure [7]. This predefined pressure is equal to 1.15 times the design 
pressure for the proof test and equal to the design pressure for the leakage rate test [4]. Thus, for the leakage rate the developed force is calculated as $514.26 \mathrm{kN}$ and $257.13 \mathrm{kN}$ for the hoop and axial direction, respectively.

\section{FINITE ELEMENT ANALYSIS}

\subsection{Modeling}

Finite element analysis (FEA) is applied to segment 2 using the commercial FEA software ABAQUS [8]. Simple supports are introduced around the bottom edge and the one lateral edge of the segment, while the load is applied with a small velocity through the top and the other lateral edge of the segment (Figure 4). The concrete is modeled using 8-noded hexahedral elements with reduced integration (C3D8R), while the reinforcement is modeled using 2-noded 3D linear truss elements (T3D2). Perfect bond is assumed between the concrete and the reinforcement and quasistatic analysis in ABAQUS/Explicit is performed using a small velocity.

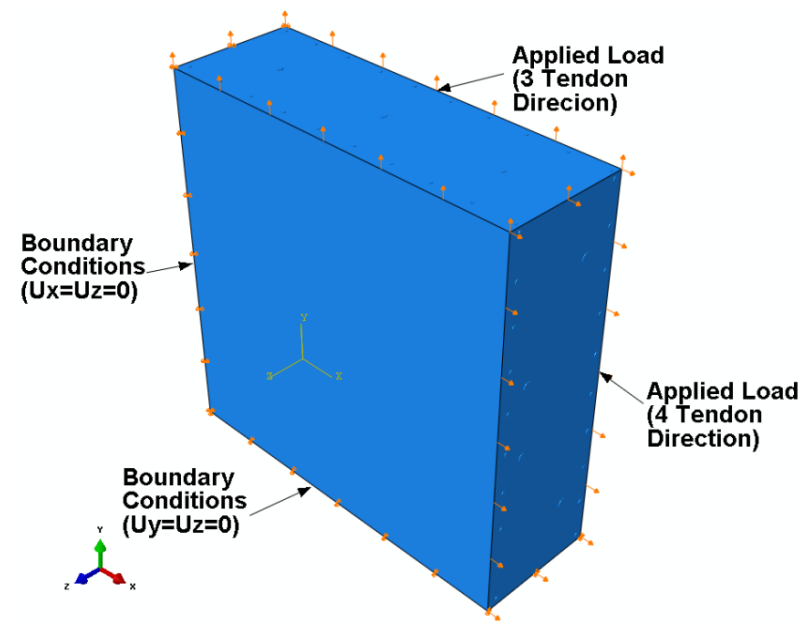

Figure 4: Boundary conditions, load and geometry of segment 2 .

The behavior of the concrete is simulated using the concrete damaged plasticity model [9]. The Poisson's ratio is set equal to $v=0.2$, the dilation angle is set equal to $\psi=36^{\circ}$, the shape factor is set equal to $K_{c}=0.667$ and the stress ratio is set equal to $\sigma_{b 0} / \sigma_{c 0}=1.16$. The tensile strength of the concrete is modelled using the fracture energy, which is calculated from the CEB-FIP MC90 [10] as $G_{f}=$ $0.0655 \mathrm{~N} / \mathrm{mm}$, based on the maximum aggregate size and the compressive strength of concrete. The fracture energy approach is selected due to the brittle behavior of the concrete in tension, since Hilleborg's fracture energy comforts adequately the tensile behavior of concrete for many practical purposes [8].

The elastic behavior of the steel (both reinforcement and tendons) is defined through the modulus of the elasticity $\left(E_{S}\right)$ and the Poisson's ratio $(v)$ with values equal to 200 $\mathrm{GPa}$ and 0.3 , respectively. The plastic behavior of the steel (both reinforcement and tendons) is defined based on an input stressstrain relationship [11].

The prestressing to the tendons is modelled by applying either initial stress or initial temperature to the tendons. Using the initial stress approach, the prestressing to the tendons is introduced in the initial step. In the following step, the end of the tendons are fully restrained, while these boundary conditions are deactivated in the subsequent step and simple supports are introduced to the bottom and to the one lateral edge of the segment. In that way, the prestressing action is taking place [12].

Using the initial temperature approach, the environmental temperature, i.e., $20^{\circ} \mathrm{C}$, is introduced to the tendons in the initial step, together with the simple supports to the bottom and to the one lateral edge of the segment. In the following step, the prestressing action is taking place by applying a new temperature value to the tendons calculated as $\Delta T=\sigma_{p e} /\left(a E_{s}\right)$, where $\sigma_{p e}$ is the prestressing in tendon, $a$ is the thermal coefficient of linear expansion of the tendon (for the steel is considered as $10^{-5} 1 /{ }^{\circ} \mathrm{C}$ ) and $E_{S}$ is the modulus of elasticity of the tendon [13]. Including the final step of the applied loads (Figure 4), the initial stress approach requires 4 steps while the initial temperature approach requires 3 steps, in total.

\subsection{Results}

The FEA results of the selected segment are 
in good agreement compared to the test results, in terms of load-strain curves, for both directions, i.e., hoop (Figure 5) and axial (Figure 6). For these load-strain curves, temperature refers to the initial temperature approach and stress refers to the initial stress approach for modeling the prestressing to the tendons. Due to the initial prestressed to the tendons, FEA records negative strains indicating that the concrete is in compression. Therefore, FEA results start from negative strains, contrary to the test results which start from zero strain, similar to relevant literature [11].

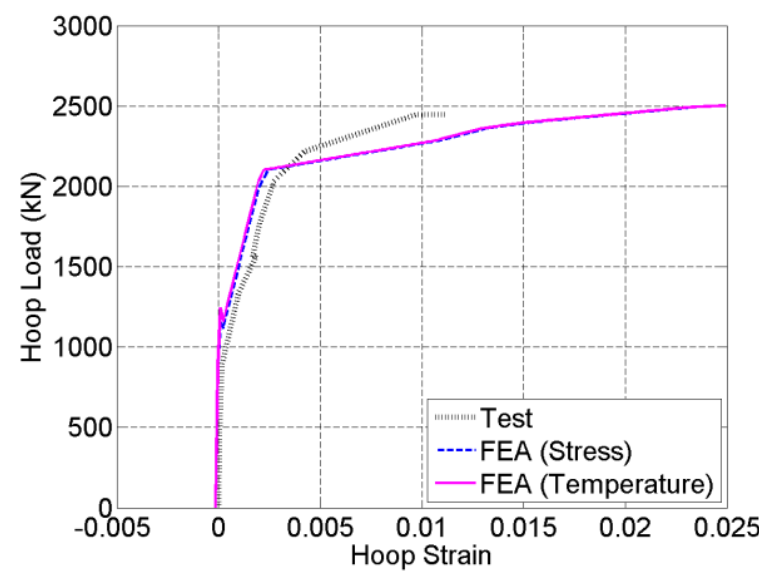

Figure 5: Curves of load-strain: Hoop direction of segment 2.

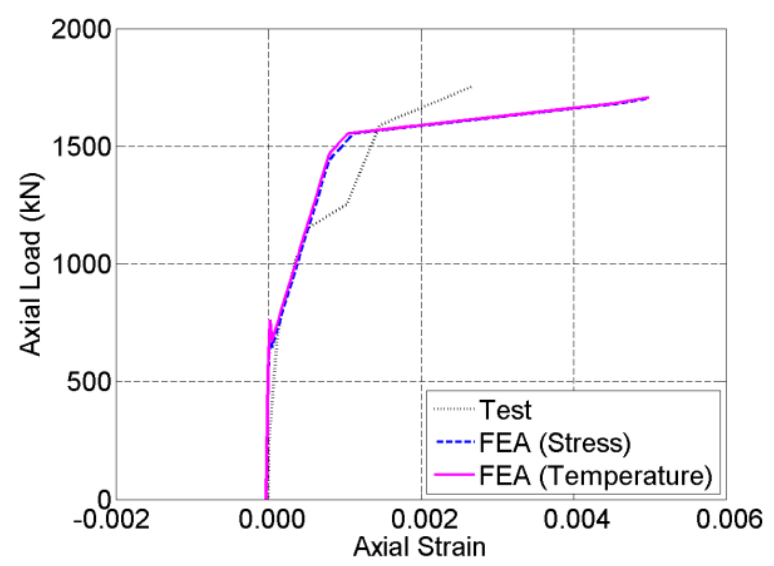

Figure 6: Curves of load-strain: Axial direction of segment 2.

\section{PROBABILISTIC ANALYSIS}

\subsection{Monte Carlo simulation}

Probabilistic FEA is applied using the Monte Carlo simulation (MCS). The material properties and the prestressing loss in hoop and axial direction are considered as uncertain, leading to 15 statistically independent random variables in total, while all the random variables are considered to follow the Normal distribution.

The coefficient of variation $(\mathrm{COV})$ of the prestressing force can be considered as $4 \%$ for a new structure (age $<5$ years) and as $12 \%$ for an old structure (age $>30$ years) [14]. This increased $\mathrm{COV}$ is reflecting the variability of the long-time losses mechanisms [15]. Thus, in this study the COV is slightly increased to $15 \%$ for the hypothetical prestressing loss scenario for an old structure (Table 4).

MCS is applied with $10^{3}$ trials for each prestressing loss scenario and the ABAQUS results are stored in terms of load-strain values. Since ABAQUS is a deterministic FEA software, python programing is used for developing the deterministic FE model and then for updating the uncertain input parameters of each FE simulation [16].

Table 1: Statistics of concrete for segment 2

\begin{tabular}{ccc}
\hline RV & Mean & COV \\
\hline$f_{c}^{\prime}$ & $31 \mathrm{MPa}$ & 0.14 \\
\hline$f_{t}^{\prime}$ & $1.85 \mathrm{MPa}$ & 0.14 \\
\hline$E_{c}$ & $27027 \mathrm{MPa}$ & 0.08 \\
\hline$\gamma_{c}$ & $24 \mathrm{kN} / \mathrm{m}^{3}$ & 0.03 \\
\hline
\end{tabular}

Note: $\mathrm{RV}=$ random variable; $\mathrm{COV}=$ coefficient of variation; $f_{c}^{\prime}=$ compressive strength of concrete; $f_{t}^{\prime}=$ tensile strength of concrete; $E_{c}=$ modulus of elasticity of concrete; $\gamma_{c}=$ density of concrete.

Table 2: Statistics of reinforcement for segment 2

\begin{tabular}{ccc}
\hline RV & Mean & COV \\
\hline$f_{y}$ & $401 \mathrm{MPa}$ & 0.04 \\
\hline$E_{s}$ & $200 \mathrm{GPa}$ & 0.033 \\
\hline$A_{s}$ & $71.2 \mathrm{~mm}^{2}$ & 0.015 \\
\hline$\gamma_{s}$ & $78 \mathrm{kN} / \mathrm{m}^{3}$ & 0.03 \\
\hline
\end{tabular}

Note: $\mathrm{RV}=$ random variable; $\mathrm{COV}=$ coefficient of variation; $f_{y}=$ yield strength of steel; $E_{s}=$ modulus of elasticity of steel; $A_{s}=$ cross-section area of steel; $\gamma_{s}=$ density of steel. 
Table 3: Statistics of tendons for segment 2

\begin{tabular}{ccc}
\hline $\mathrm{RV}$ & Mean & $\mathrm{COV}$ \\
\hline$f_{y}$ & $1627 \mathrm{MPa}$ & 0.025 \\
\hline$E_{s}$ & $200 \mathrm{GPa}$ & 0.033 \\
\hline$A_{s}$ & $38.6 \mathrm{~mm}^{2}$ & 0.015 \\
\hline$\gamma_{s}$ & $78 \mathrm{kN} / \mathrm{m}^{3}$ & 0.03
\end{tabular}

Note: $\mathrm{RV}=$ random variable; $\mathrm{COV}=$ coefficient of variation; $f_{y}=$ yield strength of steel; $E_{s}=$ modulus of elasticity of steel; $A_{s}=$ cross-section area of steel per wire (hoop direction consists of 7 wires per tendon and axial direction consists of 6 wires per tendon); $\gamma_{s}=$ density of steel.

Table 4: Statistics of prestressing loss for segment 2

\begin{tabular}{cccc}
\hline PLS & RV & Mean & COV \\
\hline \multirow{2}{*}{$3 \%$} & $P_{H}$ & $0.97 P_{H}$ & 0.04 \\
\cline { 2 - 4 } & $P_{A}$ & $0.97 P_{A}$ & 0.04 \\
\hline \multirow{2}{*}{$20 \%$} & $P_{H}$ & $0.8 P_{H}$ & 0.15 \\
\cline { 2 - 4 } & $P_{A}$ & $0.8 P_{A}$ & 0.15 \\
\hline \multirow{2}{*}{$30 \%$} & $P_{H}$ & $0.7 P_{H}$ & 0.15 \\
\cline { 2 - 4 } & $P_{A}$ & $0.7 P_{A}$ & 0.15 \\
\hline \multirow{2}{*}{$40 \%$} & $P_{H}$ & $0.6 P_{H}$ & 0.15 \\
\cline { 2 - 4 } & $P_{A}$ & $0.6 P_{A}$ & 0.15 \\
\hline
\end{tabular}

Note: $\mathrm{PLS}=$ prestressing loss scenario; RV $=$ random variable; $\mathrm{COV}=$ coefficient of variation; $P_{H}=$ 919.8 $\mathrm{MPa}$ (initial prestress after losses in hoop direction); $P_{A}=855.6 \mathrm{MPa}$ (initial prestress after losses in axial direction).

\subsection{Concrete strain distribution}

For each MCS the concrete strain can be calculated using linear interpolation, for either proof or leakage rate test. In this study, for the probabilistic analysis we consider only the leakage rate test. Thus, linear interpolation is performed for each trial and the strains are calculated, i.e., the hoop strain is calculated for $514.26 \mathrm{kN}$ and the axial strain is calculated for $257.13 \mathrm{kN}$.

Then, the normal probability paper plot is used in order to determine if the previous concrete strains follow the Normal distribution [17]. The portability paper plots indicate that the probability distribution of the calculated hoop and axial strain can be described from a Normal distribution, with mean and standard deviation as reported in the following tables (Table 5, Table 6), while here is indicatively shown the normal probability plot of the hoop strain (Figure 7) and the axial strain (Figure 8) of the $30 \%$ prestressing loss scenario.

The probability distribution of the concrete hoop and axial strain is plotted for each prestressing loss scenario, i.e., for the base case of $3 \%$ (new structure) and for the hypothetical cases of 20\%, 30\% and $40 \%$ prestressing loss (old structure). It is observed that the mean value of both hoop (Figure 9) and axial (Figure 10) strains is increased with the increase of the prestressing loss, causing the strain distribution to shift to the right. In addition, the coefficient of variation (COV) seems to indicate that the variability of the concrete strains is decreased with the increase of the prestressing loss. Thus, the concrete strains are expected to have less variability with the increase of the prestressing loss in tendons.

Table 5: Concrete hoop strain statistics: Leakage rate test for segment 2

\begin{tabular}{cccc}
\hline PLS & Mean $(\mu)$ & Stdev $(\mu)$ & COV \\
\hline $3 \%$ & 77.63 & 9.67 & 0.1245 \\
\hline $20 \%$ & 101.25 & 20.15 & 0.1990 \\
\hline $30 \%$ & 116.82 & 17.71 & 0.1516 \\
\hline $40 \%$ & 131.30 & 15.40 & 0.1173 \\
\hline
\end{tabular}

Note: PLS = prestressing loss scenario; Stdev = standard deviation; $\mathrm{COV}=$ coefficient of variation; $\mu=$ micro.

Table 6: Concrete axial strain statistics: Leakage rate test for segment 2

\begin{tabular}{cccc}
\hline PLS & Mean $(\mu)$ & Stdev $(\mu)$ & COV \\
\hline $3 \%$ & 31.53 & 5.61 & 0.1780 \\
\hline $20 \%$ & 42.78 & 13.02 & 0.3045 \\
\hline $30 \%$ & 49.89 & 10.92 & 0.2188 \\
\hline $40 \%$ & 57.33 & 9.34 & 0.1629 \\
\hline
\end{tabular}

Note: PLS $=$ prestressing loss scenario; $\operatorname{Stdev}=$ standard deviation; $\mathrm{COV}=$ coefficient of variation; $\mu=$ micro. 


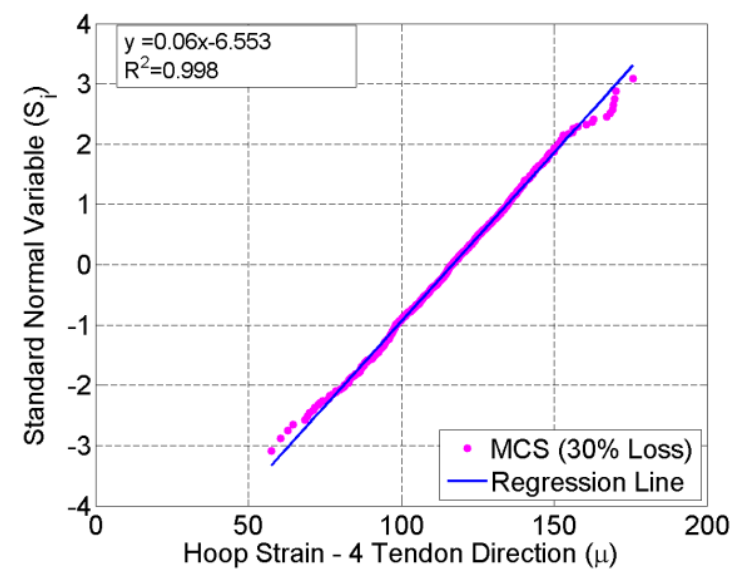

Figure 7: Normal probability paper plot: Hoop strain based on leakage rate test for $30 \%$ prestressing loss (segment 2).

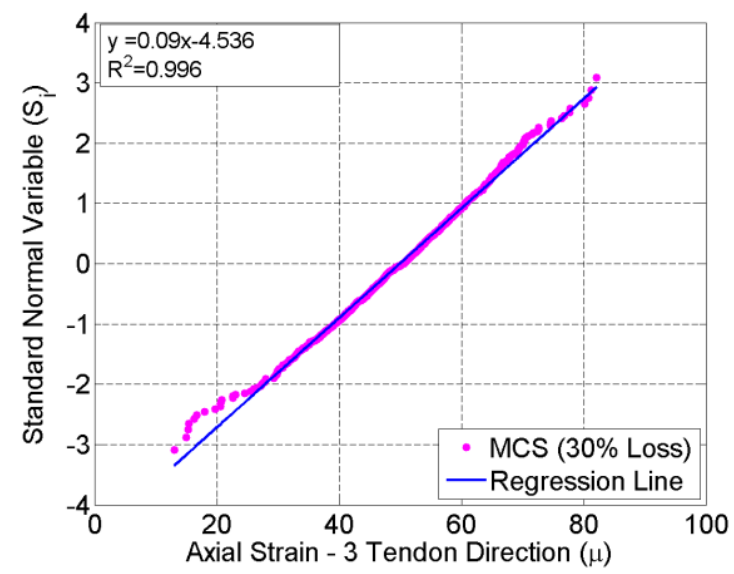

Figure 8: Normal probability paper plot: Axial strain based on leakage rate test for $30 \%$ prestressing loss (segment 2).

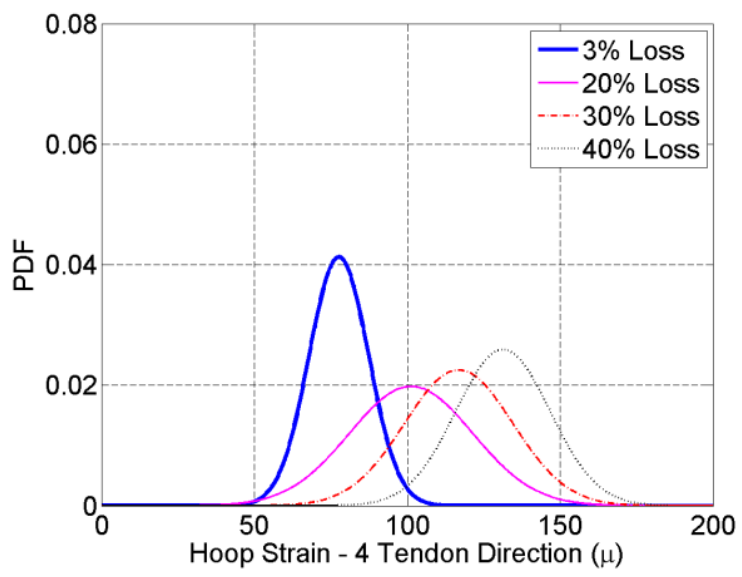

Figure 9: Hoop strain distribution: Leakage rate test for segment 2.

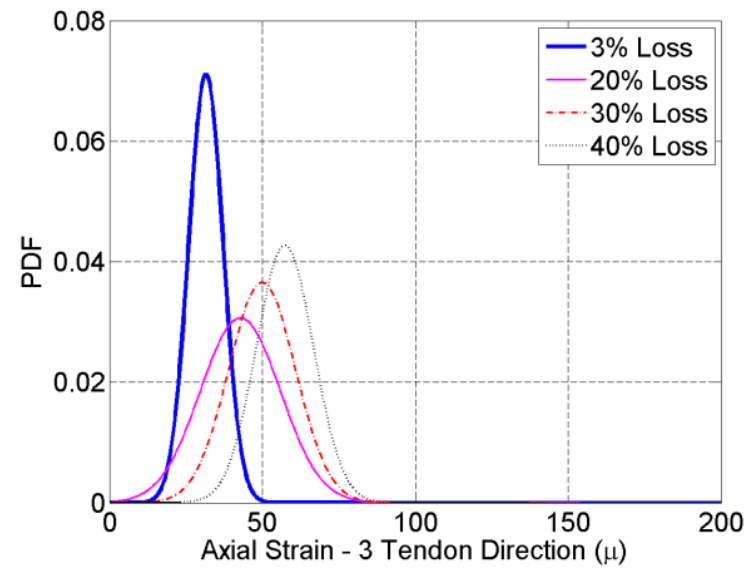

Figure 10: Hoop strain distribution: Leakage rate test for segment 2 .

\subsection{Average concrete strain}

Since the concrete strain distribution seems to be affected by the prestressing loss, the magnitude of this effect can be quantified using a parameter $\beta$ similar to the reliability index [18] as

$$
\beta=\frac{\mu_{X}-\mu_{Y}}{\sqrt{\left(\sigma_{X}\right)^{2}+\left(\sigma_{Y}\right)^{2}}}
$$

where $X$ denotes the calculated concrete strain distribution for the selected base case, i.e., $3 \%$ case here, $Y$ denotes the calculated concrete strain distribution for each hypothetical case of $20 \%, 30 \%$ and $40 \%, \mu_{X}$ is the mean value of the calculated concrete strain for the base case, $\mu_{Y}$ is the mean value of the calculated concrete strain for each hypothetical case, $\sigma_{X}$ is the standard deviation of the calculated concrete strain for the base case and $\sigma_{Y}$ is the standard deviation of the calculated concrete strain for each hypothetical case.

The probability $\mathrm{p}$ of the average concrete strain for each hypothetical scenario exceeding the average concrete strain of the $3 \%$ scenario can be calculated based on the standard Normal distribution $\Phi$, as $\mathrm{p}=\Phi(-\beta)$ [17]. The results indicate that the probability of having an increased average concrete strain is increased with the increase of the prestressing loss (Table 7, Table 8).

Thus, the average concrete strain, e.g., based on measurements during the leakage rate 
test, compared to the average strain of a selected base case, e.g., 3\%, can provide us information with respect to the prestressing loss. For instance, a 0.86 probability of the average hoop concrete strain exceeding the average concrete strain of the $3 \%$ base case indicates a $20 \%$ prestressing loss.

Table 7: Average hoop strain probability: Leakage rate test for segment 2

\begin{tabular}{ccc}
\hline PLS & $\beta$ & $\mathrm{p}=\Phi(-\beta)$ \\
\hline $3 \%$ & $\mathrm{~N} / \mathrm{A}$ & $\mathrm{N} / \mathrm{A}$ \\
\hline $20 \%$ & -1.0566 & 0.855 \\
\hline $30 \%$ & -1.9421 & 0.974 \\
\hline $40 \%$ & -2.9512 & 0.998
\end{tabular}

Note: PLS $=$ prestressing loss scenario; $\mathrm{p}=$ probability of the average concrete strain (due to prestressing loss) exceeding the average concrete strain of the $3 \%$ case.

Table 8: Average axial strain probability: Leakage rate test for segment 2

\begin{tabular}{ccc}
\hline PLS & $\beta$ & $\mathrm{p}=\Phi(-\beta)$ \\
\hline $3 \%$ & $\mathrm{~N} / \mathrm{A}$ & $\mathrm{N} / \mathrm{A}$ \\
\hline $20 \%$ & -0.7933 & 0.786 \\
\hline $30 \%$ & -1.4959 & 0.933 \\
\hline $40 \%$ & -2.3681 & 0.991 \\
\hline
\end{tabular}

Note: PLS $=$ prestressing loss scenario; $\mathrm{p}=$ probability of the average concrete strain (due to prestressing loss) exceeding the average concrete strain of the $3 \%$ case.

\section{CONCLUSIONS}

This study presents a probabilistic analysis in order to invenstigate the effect of the prestressing losses on the distribution of concrete strains. First, the deterministic finite element analysis (FEA) results indicate that the fracture energy approach, used for modeling the tensile strength of the concrete within the concrete damage plasticity model offered by ABAQUS, captures effectively the behavior of the concrete in terms of load-strain curves. Thus, fracture energy can be considered as a feasible approach for these types of problems. In addition, the deterministic results show the accuracy of the two techniques for modeling the prestressing force in tendons. However, the initial strain technique requires slightly more computational time, since one extra step has to be introduced.
Thus, the adopted initial temperature can be considered as a computational economic technique for modeling the prestressing force.

The Monte Carlo simulation (MCS) is implemented for the probabilistic analysis, since the analyzed segment does not require an extraordinary amount of computational time. However, more efficient probabilistic methods can be required for future probabilistic $\mathrm{FE}$ studies, e.g., real scale containment structures, since the computational cost can be increased.

The strain measurements during periodical inspections, i.e., proof test or leakage rate test, can provide information for the prestressing loss of bonded tendons, since the direct assessment of prestressing loss is not possible for a concrete containment structure. The probabilistic analysis results indicate that the variability of the concrete strains is expected to be decreased with the increase of the prestressing loss in tendons. Furthermore, the results indicate a high probability of increase in the average concrete strain with the increase of the prestressing loss, while this probability can be used for quantifying the prestressing loss. More cases are to be examined for further investigation of the above observations.

\section{ACKNOWLEDGEMETNS}

The authors are grateful to the University Network of Excellence in Nuclear Engineering (UNENE) and to the Natural Sciences and Engineering Research Council (NSERC) of Canada for the financial support of this study.

\section{REFERENCES}

[1] Murray, D.W., and Epstein, M. 1976. An elastic stress analysis of a Gentilly type containment structure Volume 1 , Structural Engineering Report No. 55. Department of Civil Engineering, University of Alberta, Edmonton, AB, Canada.

[2] Pandey, M.D. 1997. Reliability-based assessment of integrity of bonded prestressed concrete containment structures. Nuclear Engineering and Design 176(3): 247-260.

[3] Anderson, P. 2005. Thirty years of 
measured prestress at Swedish nuclear reactor containments. Nuclear Engineering and Design 235(21): 23232336.

[4] CSA N287.6, 2011. Pre-operational proof and leakage rate testing requirements for concrete containments structures for nuclear power plants, Canadian Standard Association, Mississauga, ON, Canada.

[5] Pandey, M.D. 1996. Proof testing of CANDU concrete containment structures, INFO-0646, Atomic Energy Control Board of Canada, Ottawa, ON, Canada.

[6] Simmonds, S.H., Rizkalla, S.H., MacGregor, J.G., 1979. Tests of wall segments from reactor containments Volume 1, Structural Engineering Report No. 81. Department of Civil Engineering, University of Alberta, Edmonton, Alberta, Canada.

[7] Hibbeler, R.C. 2011. Statics and mechanics of materials, Pearson Prentice Hall, Inc., Upper Saddle River, NJ.

[8] ABAQUS 6.12-3 2012. Abaqus analysis user's manual, Dassault Systèmes Simulia Corp., Providence, RI.

[9] Genikomsou, A.S., and Polak, M.A. 2015. Finite element analysis of punching shear of concrete slabs using damaged plasticity model in ABAQUS. Engineering Structures, 98(4): 38-48.

[10] CEB-FIP MC 90, 1993. Design of concrete structures, CEB-FIP-Model Code 1990, Thomas Telford, London, UK.

[11] Elwi, A.E., and Murray, D.W. 1980. Nonlinear analysis of axisymmetric reinforced concrete structures, Structural Engineering Report No. 87. Department of Civil Engineering, University of Alberta, Edmonton, AB, Canada.

[12] Riva, P., and Minelli, F. 2004. Numerical modelling of prestressed fiber reinforced high performance concrete beams subjected to shear. Proceedings of 5th International Conference on Fracture Mechanics of Concrete and Concrete Structures (FraMCoS-5); P0032.

[13] Ren, W., Sneed, L., Yang, Y., and He, R. 2015. Numerical simulation of prestressed precast concrete bridge deck panels using damage plasticity model. International Journal of Concrete Structures and Materials, 9(1): 45-54.

[14] Ellingwood, B.R., Galambos, T.V., MacGregor, J.G., and Cornell, C.A. 1980. Development of probabilities based load criterion for American national standard A58, NBS Special Publication No. 577, National Bureau of Standards, Washington, DC.

[15] Anderson, P., Berglund, L-E, and Gustavsson, J. 2005. Average force along unbonded tendons: a field study at nuclear reactor containments in Sweden. Nuclear Engineering and Design 235(1): 91-100.

[16] Balomenos, G.P., Genikomsou, A.S., Polak, M.A., and Pandey, M.D. 2015. Efficient method for probabilistic finite element analysis with application to reinforced concrete slabs. Engineering Structures, 103(8): 85-101.

[17] Ang, H-S.A., and Tang, H.W. 2007. Probability concepts in engineering: emphasis on applications in civil \& environmental engineering, John Wiley and Sons, Inc., Hoboken, NJ.

[18] Madsen, H.O., Krenk, S., and Lind, N.C. 1986. Methods of structural safety, Prentice Hall, Inc., Englewood Cliffs, NJ. 